\title{
$\mathrm{J}$

\section{Incorporation of an A1/A2-Difunctionalized Pillar[5]arene into a Metal-Organic Framework}

\author{
Nathan L. Strutt, ${ }^{\dagger}$ David Fairen-Jimenez, ${ }^{\ddagger}$ Julien Iehl, ${ }^{\dagger}$ Marianne B. Lalonde, ${ }^{\dagger}$ Randall Q. Snurr, ${ }^{\dagger}$ \\ Omar K. Farha, ${ }^{\dagger}$ Joseph T. Hupp,,$^{\dagger}$ and J. Fraser Stoddart ${ }^{*}{ }^{\dagger}$
}

${ }^{\dagger}$ Department of Chemistry and Department of Chemical and Biological Engineering, Northwestern University, Evanston, Illinois 60208, United States

Supporting Information

ABSTRACT: An efficient synthetic route to an A1/A2difunctionalized pillar[5] arene containing resolvable planar chirality has been developed and the arene employed as a strut in the synthesis of P5A-MOF-1, which has been demonstrated by X-ray powder diffraction analysissupported by modeling - to be isoreticular with MOF-5. This metal-organic framework has an active domain that expresses good and selective uptake of neutral and positively charged electron-poor aromatic guests, which effect color changes of the cubic crystals from faint yellow to deep orange, arising from charge transfer between the guests and active domain of P5A-MOF-1.

Tacrocycles such as cyclodextrins, ${ }^{1}$ crown ethers, ${ }^{2}$ 1 calixarenes, ${ }^{3}$ cucurbiturils, ${ }^{4}$ and cyclophanes ${ }^{5}$ have become an integral part of host-guest chemistry. ${ }^{6}$ A relatively new class of macrocycles to enter the field, the pillararenes, ${ }^{7}$ are analogues of calixarenes composed of five, six, or seven hydroquinone rings linked through their para-positions by methylene bridges. Since pillar[5] arene was first introduced as a novel macrocycle by Ogoshi and co-workers in 2008, ${ }^{7 a}$ the chemistry of the pillararenes has been developed steadily, and they have been shown to have applications in liquid crystals, ${ }^{7 q}$ artificial transmembrane channels, ${ }^{7 \mathrm{p}}$ nanoparticle formation, ${ }^{7 \mathrm{o}}$ and sensing. ${ }^{7 j}$ Here we report the synthesis of an A1/A2difunctionalized $^{8}$ pillar [5] arene that undergoes cross-coupling reactions to create a rigid strut which is then incorporated into a metal-organic framework ${ }^{9}$ (MOF) having an active domain ${ }^{10}$ containing docking sites for electron-poor guests.

MOFs with organic struts incorporating macrocycles have been used recently ${ }^{10}$ to prepare extended frameworks with active domains, which, as a result of highly favorable and specific noncovalent interactions, play host to a well-ordered distribution of guest molecules. In 2009, we described ${ }^{10 a}$ the use of a $\pi$ electron-rich BPP34C10-functionalized organic strut in the synthesis of MOF-1001 which was shown to soak up the $\pi$ electron-poor guest, methyl viologen. MOFs containing active domains show promise in the fields of chromatographic separation ${ }^{11}$ and sensing, ${ }^{12}$ thereby making designer organic struts containing novel macrocycles attractive synthetic targets.

We have developed a synthetic protocol (Scheme 1) to obtain an A1/A2-difunctionalized ${ }^{8}$ pillar[5] arene organic strut, starting from 1, which is made through the co-cyclization of 1,4dimethoxybenzene and 1,4-bis(3-bromopropoxy)benzene, sim-
Scheme 1. Synthesis of A1/A2-Difunctionalized Pillar [5] arene Organic Strut ${ }^{a}$
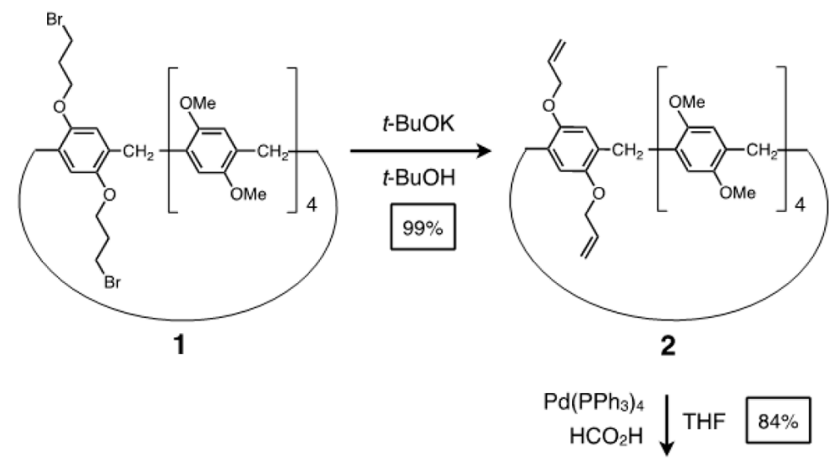

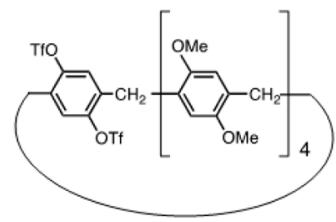

4
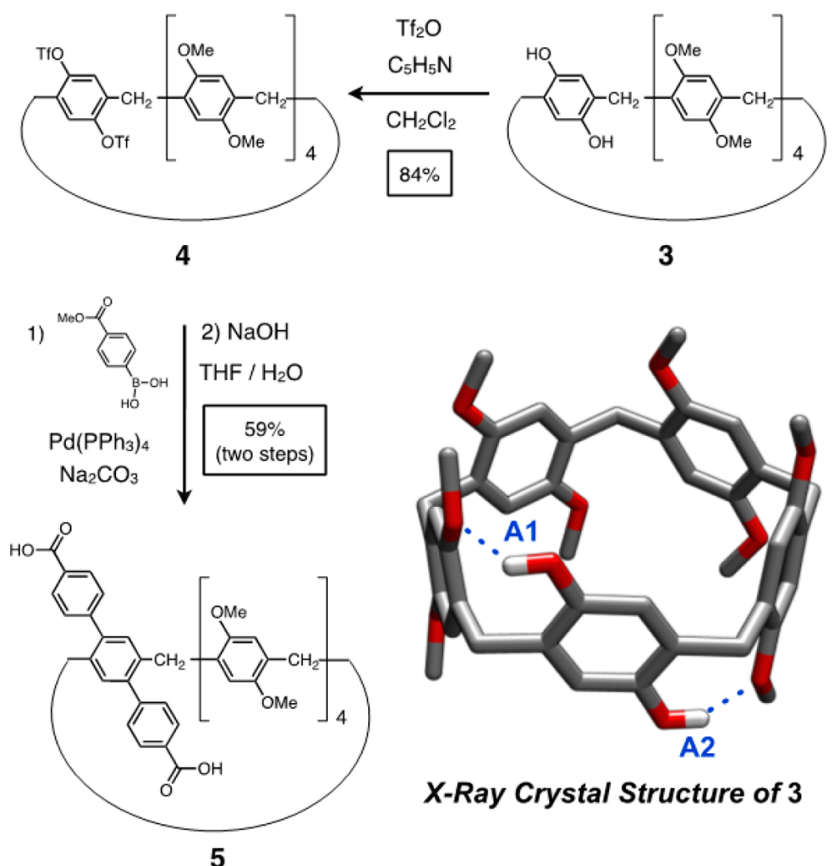

3

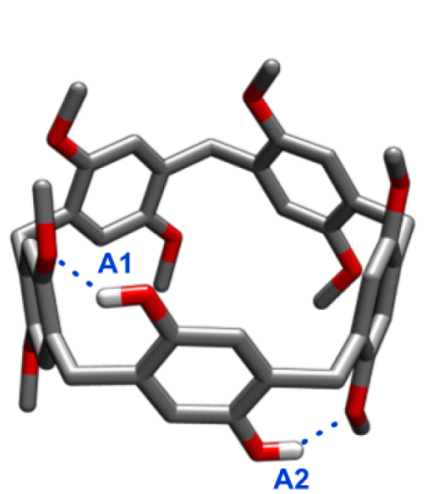

X-Ray Crystal Structure of 3
${ }^{a}$ In the $\mathrm{X}$-ray crystal structure of $3, \mathrm{C}$ is gray, $\mathrm{O}$ is red, $\mathrm{H}$ is white; alkyl $\mathrm{H}$ atoms are omitted for clarity.

ilar to our previously reported $^{7 j}$ reaction for preparing monofunctionalized pillar[5]arene. Compound 1 undergoes

Received: August 20, 2012

Published: October 1, 2012 


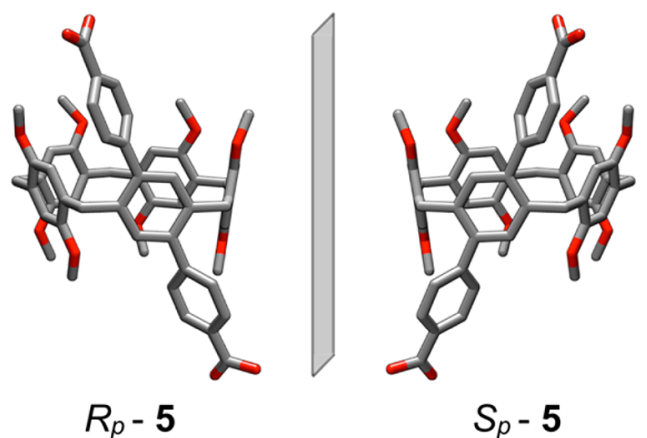

Figure 1. Solid-state structure of $\mathbf{5}$ (C is gray, $\mathrm{O}$ is red) which displays planar chirality and does not racemize between the $R_{\mathrm{p}}-5$ (left) and $S_{\mathrm{p}}-5$ (right) enantiomers. A DMF molecule and hydrogens have been removed from the structure to aid visual clarity.

elimination to give the diallyl ether 2 , which was deprotected using standard conditions ${ }^{13}$ to give the A1/A2-dihydroxypillar[5] arene 3. Single crystals of 3, suitable for X-ray crystallography, were grown; the solid-state structure ${ }^{14}$ (Scheme 1) of 3 shows that the hydroquinone unit is oriented in a direction opposite to that adopted by the 1,4-dimethoxybenzene units to support two intramolecular hydrogen bonds.

Compound 3, when treated with triflic anhydride, affords the ditriflate 4. Ogoshi and co-workers ${ }^{7 c}$ showed that a pertriflated pillar[5] arene can undergo $10 \mathrm{Pd}$-catalyzed cross-couplings to give a highly conjugated pillar[5] arene. In similar fashion, 4 can be converted into a rigid strut 5 by means of a Pd-catalyzed Suzuki reaction with 4-(methoxycarbonyl)phenylboronic acid, followed by saponification of the intermediate diester. The solidstate structure of $\mathbf{5}$ (Figure 1) was elucidated by single-crystal Xray analysis ${ }^{15}$ using crystals grown from diffusion of $\mathrm{MeOH}$ into a solution of $\mathbf{5}$ in DMF. The analysis indicates the presence of enantiomers in the unit cell. In keeping with its molecular $C_{2}$ symmetry, the ${ }^{1} \mathrm{H}$ NMR spectrum (see SI) ${ }^{16}$ of 5 displays two pairs of doublets for the two homotopic pairs of constitutionally hetereotopic methylene groups-where in each case the protons are diastereotopic, ${ }^{17}$ given the fact that $\mathbf{5}$ is conformationally rigid-and a singlet for the remaining constitutionally hetereotopic methylene group lying on the $C_{2}$ axis, which renders its methylene protons homotopic. The conformational rigidity of the pillar[5] arene-based strut 5 means that it exists as (potentially resolvable ${ }^{18,19}$ ) enantiomers, $R_{\mathrm{p}}$ and $S_{\mathrm{p}}$ (Figure 1) due to the molecule's planar chirality. ${ }^{20}$ Compound 5 demonstrates that only two bulky monosubstituted phenyl rings are required at the $\mathrm{A} 1 / \mathrm{A} 2$ positions on a pillar[5]arene to impart resolvable planar chirality ${ }^{21}$ upon its constitution.

The pillar[5] arene-based strut 5 has been used to synthesize a MOF (Figure 2a) with $\mathrm{Zn}_{4} \mathrm{O}$ secondary building units (SBUs) which is isoreticular to MOF-5. ${ }^{9 \mathrm{~b}}$ P5A-MOF-1 was prepared in a conventional manner by heating a mixture of $\mathbf{5}$ and $\mathrm{Zn}$ $\left(\mathrm{NO}_{3}\right)_{2} \cdot 6 \mathrm{H}_{2} \mathrm{O}$ in DMF at $100{ }^{\circ} \mathrm{C}$ over $24 \mathrm{~h}$. The crystals (Figure 3a) of P5A-MOF-1 are cubic and transparent. Powder X-ray diffraction (PXRD) confirmed their crystallinity (Figure 2b), while thermal gravimetric analysis (TGA) was performed to determine their thermal stability: a one-step TGA profile shows that P5A-MOF-1 is stable to $450{ }^{\circ} \mathrm{C}$. Crystals of P5A-MOF-1 were activated using supercritical $\mathrm{CO}_{2}$, and a NLDFT surface area of $300 \mathrm{~m}^{2} \mathrm{~g}^{-1}$ was obtained from a $\mathrm{CO}_{2}$ isotherm (see SI).

Single-crystal X-ray data obtained for P5A-MOF-1 were not well enough resolved to discern the solid-state structure of the extended framework as a result of disorder within the MOF itself.
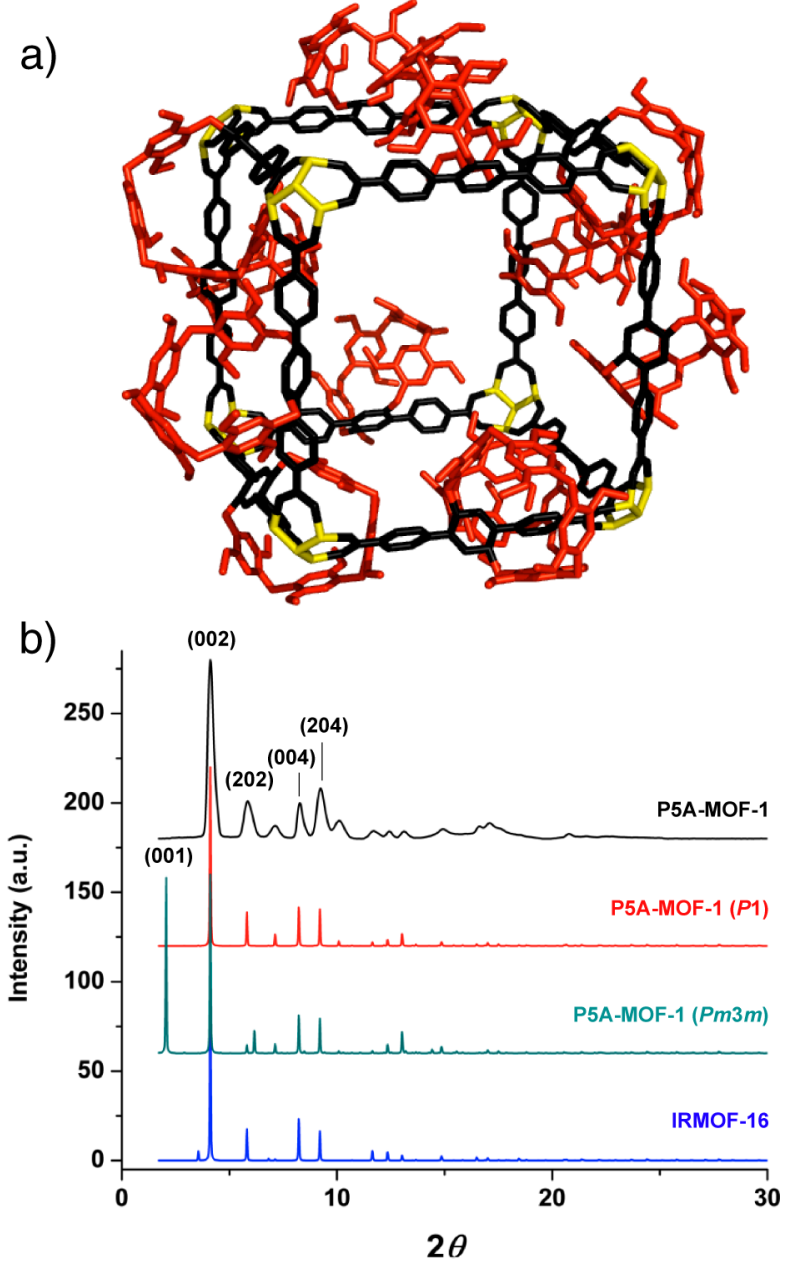

Figure 2. (a) Model of P5A-MOF-1 (pillar[5] arene macrocycles are red, terphenylene moieties are black, zinc SBUs are yellow). (b) Experimental PXRD pattern for P5A-MOF-1 (black), calculated PXRD patterns for P5A-MOF-1 in a $P 1$ space group (red) and a $P m 3 m$ space group (green), and PXRD pattern for IRMOF-16 (blue). See SI for full PXRD of P5A-MOF-1.

We believe this disorder arises principally from the rotational freedom of pillar[5] arenes around every terphenylene linker in the extended structure and a random distribution of "enantiomeric" pillar[5] arenes associated with their planar chirality.

The extended structure of P5A-MOF-1 was modeled (see SI) using non-interpenetrated IRMOF- $16^{9 \mathrm{e}}$ as the backbone and incorporating pillar[5]arenes with randomly distributed chiralities and orientations with respect to the terphenylene linkers. The geometry of the predicted structure was optimized to give a cubic unit cell with dimensions of $a=b=c=42.980 \AA$ and a space group of $P 1$. The simulated PXRD pattern of the modeled structure matches closely with the experimental one for P5AMOF-1 (Figure 2b). An alternative approach to modeling the extended structure with a $P m 3 m$ space group was also pursued to determine if a model with higher symmetry might also fit the experimental MOF data. In this alternative model, each organic strut, ordered throughout the 3D framework, contains four pillar[5] arene rings in the shape of both "enantiomers" in two different orientations, each with a 0.25 occupancy disorder. Although the cubic cell dimensions of the model are identical with those of the first model, the simulated PXRD pattern presents extra peaks (Figure 2b), including a sharp 001 reflection. 

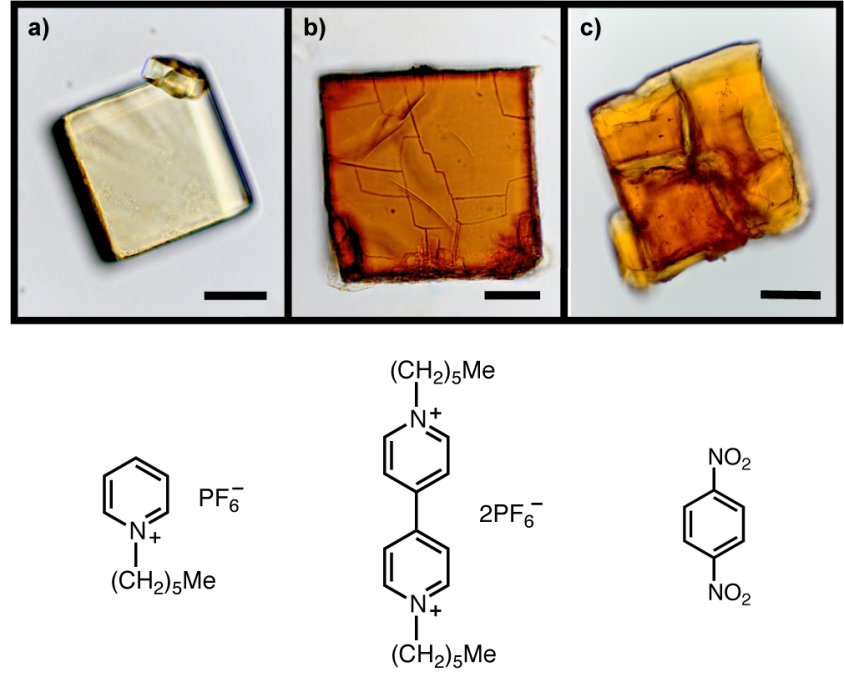

\section{$\mathbf{G 1} \cdot \mathrm{PF}_{6}^{-} \quad \mathbf{G} 2 \cdot 2 \mathrm{PF}_{6}^{-} \quad$ G3}

Figure 3. (Top) Optical microscopy images of P5A-MOF-1 (a) with no guest (scale bar, $200 \mu \mathrm{m}$ ), (b) after uptake of $\mathbf{G} 2 \cdot 2 \mathrm{PF}_{6}$ (scale bar, 100 $\mu \mathrm{m}$, and (c) after uptake of $\mathbf{G} 3$ (scale bar, $100 \mu \mathrm{m}$ ). (Bottom) Electronpoor compounds used in guest uptake studies with P5A-MOF-1: $\mathrm{N}$ hexylpyridinium cation $\left(\mathbf{G 1}^{+}\right), N, N^{\prime}$-dihexyl-4,4-bipyridinium dication $\left(\mathbf{G 2}^{2+}\right)$, and 1,4-dinitrobenzene (G3).

Thus, it seems that the lower symmetry model provides a better match with the experimental data.

We investigated the ability of P5A-MOF-1 to take up guests (Figure 3). At the outset, however, we evaluated the ability of the strut 5 to form complexes with three guests: ${ }^{22}$ the $\mathrm{PF}_{6}{ }^{-}$salts of $\mathrm{N}$ hexylpyridinium cation $\left(\mathbf{G 1}^{+}\right)$and $N, N^{\prime}$-dihexyl-4,4-bipyridinium dication $\left(\mathbf{G 2}^{2+}\right)$, as well as the neutral 1,4-dinitrobenzene (G3). ${ }^{1} \mathrm{H}$ NMR titrations in $\mathrm{CD}_{3} \mathrm{COCD}_{3}$ revealed association constants $\left(K_{\mathrm{a}}\right)$ between $\mathbf{5}$ and $\mathbf{G 1} \cdot \mathrm{PF}_{6}, \mathbf{G} 2 \cdot 2 \mathrm{PF}_{6}$, and $\mathbf{G} 3$ of 43.2 $\pm 2.9,170 \pm 50$, and $66.2 \pm 1.9 \mathrm{M}^{-1}$, respectively.

Samples of P5A-MOF-1 were suspended in $\mathrm{Me}_{2} \mathrm{CO}$ prior to guest uptake experiments to remove excess of DMF from within the framework. The samples were then introduced into saturated solutions of G1 $\cdot \mathrm{PF}_{6}, \mathbf{G} 2 \cdot 2 \mathrm{PF}_{6}$, and $\mathbf{G} 3$ in $\mathrm{Me}_{2} \mathrm{CO}$. With $\mathbf{G} 2 \cdot 2 \mathrm{PF}_{6}$ and G3, the crystals underwent an immediate color change (Figure $3 b, c$ ) from faint yellow to deep orange upon addition of the guests, most likely because of charge-transfer interactions between the guests and P5A-MOF-1. The MOF samples were allowed to take up guests for $12 \mathrm{~h}$ before they were washed with $\mathrm{Me}_{2} \mathrm{CO}$ and dissolved in DMSO- $d_{6} /$ TFA- $d$ and their ${ }^{1} \mathrm{H}$ NMR spectra recorded. Integration of appropriate probe protons led to quantification of the uptake of guests by the MOF (Table 1). IRMOF-16-OPX, prepared from an oligo-p-xylene (OPX) derivative $^{23}$ (S3 in SI) of $p$-terphenyl-4,4"-dicarboxylic acid, ${ }^{24}$ was used as a control. Although both P5A-MOF-1 and IRMOF16-OPX are isoreticular with IRMOF-16, the latter does not have an active domain. The guest uptake experiments were performed under identical conditions for both MOFs.

P5A-MOF-1 takes up G1·PF, G2 $2 \mathrm{PF}_{6}$, and G3 from their saturated solutions in $\mathrm{Me}_{2} \mathrm{CO}$ in moderate to high amounts. Table 1 lists the mole ratios of the guest to the organic strut found in the MOF. The fact that, under identical conditions, P5AMOF-1 takes up a significantly larger amount of each guest than does IRMOF-16-OPX suggests the active domain of P5A-MOF$\mathbf{1}$ is able to interact with guest molecules through favorable noncovalent bonding interactions. Uptake of adamantane, which
Table 1. Mole Ratio of Guest to Organic Strut in P5A-MOF-1 and IRMOF-16-OPX, Obtained from ${ }^{1} \mathrm{H}$ NMR Spectra after Guest Uptake and Digestion of $\mathrm{MOF}^{a}$

\begin{tabular}{|c|c|c|}
\hline & P5A-MOF-1 & IRMOF-16-OPX \\
\hline \multicolumn{3}{|c|}{ Single-Guest Uptake Experiments } \\
\hline $\mathrm{G1}^{+}$ & 0.755 & 0.121 \\
\hline $\mathbf{G}^{2+}$ & 0.366 & 0.125 \\
\hline G3 & 0.293 & 0.084 \\
\hline \multicolumn{3}{|c|}{ Two-Guest Uptake Experiments } \\
\hline $\mathrm{G1}^{+}+\mathbf{G}^{2+}$ & $0.091 \mathrm{G1}^{+} / 0.176 \mathrm{G}^{2+}$ & $0.089 \mathrm{G1}^{+} / 0.069 \mathrm{G}^{2+}$ \\
\hline $\mathbf{G 1}^{+}+\mathbf{G} 3$ & $0.090 \mathrm{G1}^{+} / 0.127 \mathrm{G} 3$ & $0.027 \mathrm{G1}^{+} / 0.032 \mathrm{G} 3$ \\
\hline $\mathrm{G}^{2+}+\mathbf{G} 3$ & $0.310 \mathrm{G}^{2+} / 0.100 \mathrm{G} 3$ & $0.068 \mathrm{G2}^{2+} / 0.014 \mathrm{G} 3$ \\
\hline
\end{tabular}

${ }^{a}$ Uptake with a single guest was performed with a saturated solution of the guest in $\mathrm{Me}_{2} \mathrm{CO}$. Uptake with two guests was performed in a $\mathrm{Me}_{2} \mathrm{CO}$ solution with each guest at $40.0 \mathrm{mM}$. $K_{\mathrm{a}}$ values of guest with 5 determined by ${ }^{1} \mathrm{H}$ NMR titration in $\mathrm{CD}_{3} \mathrm{COCD}_{3}: \mathbf{G 1}^{+}, 43.2 \pm 2.9$ $\mathrm{M}^{-1} ; \mathrm{G2}^{2+}, 170 \pm 50 \mathrm{M}^{-1}$; G3, $66.2 \pm 1.9 \mathrm{M}^{-1}$.

has been shown ${ }^{7 a}$ to be too large to reside inside the cavity of pillar[5]arene, but small enough to pass through the pores of either MOF, was similar for both P5A-MOF-1 and IRMOF-16OPX (see SI).

In a final experiment, P5A-MOF-1 was suspended in $\mathrm{Me}_{2} \mathrm{CO}$ with equimolar concentrations $(40.0 \mathrm{mM})$ of two different guests to determine if there is preferential uptake of one guest over the other. While we envisioned that the observed guest-to-MOF ratios would depend to some extent on the $K_{\mathrm{a}}$ values of the guests with $\mathbf{5}$ in solution, other factors, including the sizes and diffusion rates of the guests, might also be significant. P5A-MOF-1 showed almost twice the uptake of $\mathbf{G} 2 \cdot 2 \mathrm{PF}_{6}$ compared to $\mathrm{G} \mathbf{1} \cdot \mathrm{PF}_{6}$ (Table 1), reflecting the larger $K_{\mathrm{a}}$ value for the former than the latter in binding $\mathbf{5}$. Under identical conditions, the uptake by IRMOF-16-OPX of these two guests is very similar, as expected. Comparable results, which reflect ratios of $K_{\mathrm{a}}$ values, can be observed when P5A-MOF-1 is exposed to equimolar combinations of the other guests (Table 1).

The rigid stereochemistry associated with the planar chirality of the strut $\mathbf{5}$ means that it should be possible, after resolving $\mathbf{5}$, to prepare "enantiomeric" P5A-MOF-1 samples without fear of $\mathbf{5}$ racemizing during the synthesis (at $100{ }^{\circ} \mathrm{C}$ ) of the MOF. The prospect of being able to prepare chiral, enantiomerically pure, pillar[5] arene-containing MOFs to separate racemic mixtures of appropriate analytes is being pursued in our laboratories.

\section{ASSOCIATED CONTENT}

Supporting Information

Experimental details, modeling, and characterization. This material is available free of charge via the Internet at http:// pubs.acs.org.

\section{AUTHOR INFORMATION}

\section{Corresponding Author}

stoddart@northwestern.edu

Notes

The authors declare no competing financial interest.

\section{ACKNOWLEDGMENTS}

The authors thank Benjamin Moritz for performing the chiral HPLC studies, Dr. Amy Sarjeant and Dr. Charlotte Stern for performing the PXRDs and single-crystal X-ray crystallography data collection, and Dr. Saman Shafie for performing the mass spectrometry experiments. This work was supported by the Non- 
Equilibrium Energy Research Center, which is an Energy Frontier Research Center funded by the U.S. Department of Energy, Offices of Basic Energy Sciences, under Award No. DESC0000989. R.Q.S. acknowledges support from the Defense Threat Reduction Agency (HDTRA1-10-1-0023) J.T.H. and O.K.F. gratefully acknowledge financial support from the Defense Threat Reduction Agency (grant No. HDTRA1-09-10007). N.L.S. thanks the National Science Foundation for a Graduate Research Fellowship.

\section{REFERENCES}

(1) Schardinger, F. Z. Lebensm. Forsch. A 1903, 6, 865. D'Souza, V. T.; Lipkowitz, K. B. Chem. Rev. 1998, 98, 1741. Harada, A.; Hashidzume, A.; Yamaguchi, H.; Takashima, Y. Chem. Rev. 2009, 109, 5974.

(2) Pedersen, C. J. J. Am. Chem. Soc. 1967, 89, 2495. Truter, M. R. Struct. Bonding 1973, 16, 71. Pedersen, C. J. Angew. Chem., Int. Ed. 1998, 27, 1021. Stoddart, J. F. Top. Stereochem. 1987, 17, 207. Cantrill, S. J.; Pease, A. R.; Stoddart, J. F. J. Chem. Soc., Dalton Trans. 2000, 21, 3715.

(3) Gutsche, C. D. Calixarenes; Royal Society of Chemistry: Cambridge, UK, 1989. Böhmer, V. Angew. Chem., Int. Ed. 1995, 34, 713. Kim, H. J.; Lee, M. H.; Mutihac, L.; Vicens, J.; Kim, J. S. Chem. Soc. Rev. 2012, 41, 1173.

(4) Freeman, W. A.; Mock, W. L.; Shih, N. Y. J. Am. Chem. Soc. 1981, 103, 7367. Mock, W. L.; Shih, N. Y. J. Am. Chem. Soc. 1988, 110, 4706. Masson, E.; Ling, X.; Joseph, R.; Kyeremeh-Mensah, L.; Lu, X. RSC Adv. 2012, 2, 1213.

(5) Diederich, F. Angew. Chem., Int. Ed. 1988, 27, 362. Gleiter, R; Hopf, H. Modern Cyclophane Chemistry; Wiley-VHC: Weinheim, 2004. (6) Cram, D. J.; Cram, J. M. Science 1974, 183, 803. Cram, D. J. Angew. Chem., Int. Ed. 1998, 27, 1009. Cram, D. J.; Cram, J. M. Container Molecules and Their Guests; Royal Society of Chemistry: Cambridge, UK, 1994.

(7) (a) Ogoshi, T.; Kanai, S.; Fujinami, S.; Yamagishi, T.-a.; Nakamoto, Y. J. Am. Chem. Soc. 2008, 130, 5022. (b) Cao, D.; Kou, Y.; Liang, J.; Chen, Z.; Wang, L.; Meier, H. Angew. Chem., Int. Ed. 2009, 48, 9721. (c) Ogoshi, T.; Umeda, K.; Yamagishi, T.-a.; Nakamoto, Y. Chem. Commun. 2009, 4874. (d) Zhang, Z.; Xia, B.; Han, C.; Yu, Y.; Huang, F. Org. Lett. 2010, 12, 3285. (e) Han, C.; Ma, F.; Zhang, Z.; Xia, B.; Yu, Y.; Huang, F. Org. Lett. 2010, 12, 4360. (f) Ogoshi, T.; Nishida, Y.; Yamagishi, T.-a.; Nakamoto, Y. Macromolecules 2010, 43, 7068. (g) Ogoshi, T.; Kitajima, K.; Aoki, T.; Yamagishi, T.-a.; Nakamoto, Y. J. Phys. Chem. Lett. 2010, 1, 817. (h) Ogoshi, T.; Aoki, T.; Kitajima, K.; Fujinami, S.; Yamagishi, T.-a.; Nakamoto, Y. J. Org. Chem. 2011, 76, 328. (i) Aoki, T.; Ogoshi, T.; Yamagishi, T. Chem. Lett. 2011, 40, 795. (j) Strutt, N. L.; Forgan, R. S.; Spruell, J. M.; Botros, Y. Y.; Stoddart, J. F. J. Am. Chem. Soc. 2011, 133, 5668. (k) Zhang, H.; Strutt, N. L.; Stoll, R. S.; Li, H.; Zhu, Z.; Stoddart, J. F. Chem. Commun. 2011, 47, 11420. (1) Hu, X.-B.; Chen, L.; Si, W.; Yu, Y.; Hou, J.-L. Chem. Commun. 2011, 47, 4694. (m) Strutt, N. L.; Zhang, H.; Giesener, M. A.; Lei, J.; Stoddart, J. F. Chem. Commun. 2012, 48, 1647. (n) Cragg, P. J.; Sharma, K. Chem. Soc. Rev. 2012, 41, 597. (o) Yao, Y.; Xue, M.; Chi, X. D.; Ma, Y. J.; He, J. M.; Abliz, Z.; Huang, F. H. Chem. Commun. 2012, 48, 6505. (p) Hu, C. B.; Chen, Z. X.; Tang, G. F.; Hou, J. L.; Li, Z. T. J. Am. Chem. Soc. 2012, 134, 8384. (q) Nierengarten, I.; Guerra, S.; Holler, M.; Nierengarten, J.F.; Deschenaux, R. Chem. Commun. 2012, 48, 8072.

(8) A nomenclature system for identifying the hydroxyl groups in pillararenes has been introduce by Ogoshi and co-workers. The letters refer to the hydroquinone units, while the numbers refer to the rims of the macrocycle. Ogoshi, T.; Kitajima, K.; Fujinami, S.; Yamagishi, T.-a. Chem. Commun. 2011, 47, 10106.

(9) (a) Yaghi, O. M.; Li, G. M.; Li, H. L. Nature 1995, 378, 703. (b) Li, H.; Eddaoudi, M.; O’Keeffe, M.; Yaghi, O. M. Nature 1999, 402, 276. (c) Seo, J. S.; Whang, D.; Lee, H.; Jun, S. I.; Oh, J.; Jeon, Y. J.; Kim, K. Nature 2000, 404, 982. (d) Eddaoudi, M.; Moler, D. B.; Li, H. L.; Chen, B. L.; Reineke, T. M.; O’Keeffe, M.; Yaghi, O. M. Acc. Chem. Res. 2001, 34, 319. (e) Eddaoudi, M.; Kim, J.; Rosi, N.; Vodak, D.; Wachter, J.; O’Keeffe, M.; Yaghi, O. M. Science 2002, 295, 469. (f) Kitagawa, S.; Kitaura, R.; Noro, S. Angew. Chem., Int. Ed. 2004, 43, 2334. (g) Murray,
L. J.; Dinca, M.; Long, J. R. Chem. Soc. Rev. 2009, 38, 1294. (h) Lee, J.; Farha, O. K.; Roberts, J.; Scheidt, K. A.; Nguyen, S. T.; Hupp, J. T. Chem. Soc. Rev. 2009, 38, 1450. (i) Wilmer, C. E.; Leaf, M.; Lee, C. Y.; Farha, O. K.; Hauser, B. G.; Hupp, J. T.; Snurr, R. Q. Nat. Chem. 2012, 4, 83. (j) Deng, H.; Grunder, S.; Cordova, K. E.; Valente, C.; Furukawa, H.; Hmadeh, M.; Gándara, F.; Whalley, A. C.; Liu, Z.; Asahina, S.; Kazumori, H.; O'Keeffe, M.; Terasaki, O.; Stoddart, J. F.; Yaghi, O. M. Science 2012, 336, 1018. (k) Vukotic, V. N.; Harris, K. J.; Zhu, K.; Schurko, R. W.; Loeb, S. J. Nat. Chem. 2012, 4, 456.

(10) (a) Li, Q. W.; Zhang, W. Y.; Miljanic, O. S.; Sue, C. H.; Zhao, Y. L.; Liu, L. H.; Knobler, C. B.; Stoddart, J. F.; Yaghi, O. M. Science 2009, 325, 855. (b) Valente, C.; Choi, E.; Belowich, M. E.; Doonan, C. J.; Li, Q.; Gasa, T. B.; Botros, Y. Y.; Yaghi, O. M.; Stoddart, J. F. Chem. Commun. 2010, 46, 4911. (c) Deng, H.; Olson, M. A.; Stoddart, J. F.; Yaghi, O. M. Nat. Chem. 2010, 2, 439.

(11) Han, S.; Wei, Y.; Valente, C.; Lagzi, I.; Gassensmith, J. J.; Coskun, A.; Stoddart, J. F.; Grzybowski, B. A. J. Am. Chem. Soc. 2010, 132, 16358.

(12) Lu, G.; Hupp, J. T. J. Am. Chem. Soc. 2010, 132, 7832. Kreno, L. E.; Leong, K.; Farha, O. K.; Allendorf, M.; Van Duyne, R. P.; Hupp, J. T. Chem. Rev. 2012, 112, 1105.

(13) Hey, H.; Arpe, H.-J. Angew. Chem., Int. Ed. 1973, 12, 928.

(14) Crystal data for 3: $\mathrm{C}_{43} \mathrm{H}_{46} \mathrm{O}_{10}$, red prism, $0.070 \times 0.207 \times 0.219$ $\mathrm{mm}^{3}$; monoclinic, space group C2; $a=21.2730(3), b=11.9713(2)$, and $c=17.7886(2) \AA ; \beta=99.5880(10)^{\circ} ; V=4466.8(6) \AA^{3} ; T=100(2) \mathrm{K}, Z$ $=4, \rho_{\text {calc }}=1.075 \mathrm{~g} \mathrm{~cm}^{-3}, \mu(\mathrm{Cu} \mathrm{K} \alpha)=0.621 \mathrm{~mm}^{-1}, F(000)=1536.0$; independent measured reflections, $24167 ; R 1=0.0645$ and $w R_{2}=$ 0.2036 for 7579 independent observed reflections $\left[2 \theta \leq 124^{\circ}, I>\right.$ $2 \sigma(I)]$. CCDC 896923.

(15) Crystal data for 5: $\mathrm{C}_{57} \mathrm{H}_{54} \mathrm{O}_{12}\left(\mathrm{C}_{3} \mathrm{H}_{7} \mathrm{NO}\right)$, colorless column, 0.074 $\times 0.130 \times 0.430 \mathrm{~mm}^{3}$, monoclinic, space group $P 22_{1} / c ; a=14.5211(2), b$ $=34.3107(4)$, and $c=11.87650(10) \AA ; \beta=97.2640(10)^{\circ} ; V=$ $5869.73(12) \AA^{3} ; T=100(2) \mathrm{K}, Z=4, \rho_{\text {calc }}=1.069 \mathrm{~g} \mathrm{~cm}^{-3}, \mu(\mathrm{Cu} \mathrm{K} \alpha)=$ $0.612 \mathrm{~mm}^{-1}, F(000)=2128$; independent measured reflections, 39135 ; $R 1=0.0669$ and $w R_{2}=0.1648$ for 10348 independent observed reflections $\left[2 \theta \leq 124^{\circ}, I>2 \sigma(I)\right]$. CCDC 896924 .

(16) Two-dimensional NOESY was employed in the assignment of the 1-D ${ }^{1} \mathrm{H}$ NMR spectrum (see SI).

(17) Even at elevated temperatures $\left(100{ }^{\circ} \mathrm{C}\right)$ exchange between the diastereotopic methylene protons is not observed, indicating that the two benzoic acid substituents of $\mathbf{5}$ render the strut too large to be able to pass through the middle of the annulus which constitutes pillar [5] arene, implying that the inversion between the $R_{\mathrm{p}}$ and $S_{\mathrm{p}}$ enantiomers (Figure 1) does not occur on the NMR time scale, or indeed it would appear, on the laboratory time scale.

(18) At room temperature, the ${ }^{1} \mathrm{H}$ NMR spectra (see SI) for $\mathbf{1 - 4}$ all display three singlets corresponding to the constiutionally heterotopic methylene groups, indicating that the enantiomeric pairs of these pillar[5] arene derivatives are inverting rapidly on the ${ }^{1} \mathrm{H}$ NMR time scale.

(19) Further proof that the $R_{\mathrm{p}}$ and $S_{\mathrm{p}}$ enantiomers of 5 are resolvable comes from its ${ }^{1} \mathrm{H}$ NMR spectrum (see SI) after addition of a resolving agent-the alkaloid (-)-cinchonidine-revealing multiple resonances for protons, diastereotopic by external comparison, present in the diastereoisomeric acid-base pair (salts).

(20) Further discussion on the planar chirality of pillar[5]arene: Ogoshi, T.; Masaki, K.; Shiga, R.; Kitajima, K.; Yamagishi, T.-a. Org. Lett. 2011, 13, 1264

(21) The ${ }^{1} \mathrm{H}$ NMR spectrum of the dimethyl ester ( $\mathbf{S} \mathbf{1}$ in SI) of $\mathbf{5}$ indicates that it is also, as expected, conformationally rigid and so exists as resolvable enantiomers which, in this instance, have been separated (resolved) by chiral HPLC.

(22) Guests similar to $\mathbf{G 1}^{+}$and $\mathbf{G} 2^{2+}$ have previously been reported to bind inside the cavity of pillar[5]arene and the electron/poor nature of G3 also makes it a suitable guest for 5. See: Ogoshi, T. J. Incl. Phenom. Macro. 2012, 72, 247.

(23) The four methyl groups present in S3 enhance its solubility in organic solvents.

(24) Grunder, S.; Stoddart, J. F. Chem. Commun. 2012, 48, 3158. 